\title{
Transamniotic stem cell therapy: a novel strategy for the prenatal management of congenital anomalies
}

\author{
Dario O Fauza ${ }^{1}$
}

Transamniotic stem cell therapy, or TRASCET, is an emerging therapeutic concept for the management of congenital anomalies based on the augmentation of the biological role of select populations of stem cells that already occur in the amniotic fluid, for targeted therapeutic benefit. Amniotic fluidderived mesenchymal stem cells (afMSCs) have a central role in the enhanced ability of the fetus to repair tissue damage. This germane recent finding constitutes the biological foundation for the use of afMSCs in TRASCET. It has been shown experimentally that simple intra-amniotic delivery of afMSCs in large numbers can either elicit the repair, or significantly mitigate the effects associated with major congenital anomalies by boosting the activity that these cells normally have. For example, TRASCET can induce partial or complete coverage of experimental spina bifida by promoting the local formation of host-derived skin, thus protecting the spinal cord from further damage. In another example, it can significantly alleviate the bowel damage associated with gastroschisis, one of the most common major abdominal wall defects. Other applications involving different congenital anomalies and/or other stem cells present in the amniotic fluid in diseased pregnancies are currently under investigation in this freshly evolving facet of fetal stem cell therapy.

$\mathbf{T}$ ransamniotic stem cell therapy (TRASCET) is a therapeutic concept pertinent to fundamentally diverse birth defects, first reported experimentally in a translational approach only as recently as 2014 and not yet trialed clinically as of this writing. Its biological basis is centered on the normal role played by specific populations of stem cells that either naturally occur in the amniotic fluid, or are present therein during certain pathological states. The appeal and viability of plain intra-amniotic administrations of large concentrations of select (typically autologous) stem cells as a means to boost the normal activity of such cells and in turn deliver therapeutic benefit at minimal to no risk to the mother and fetus is self-explanatory. Such a practicable intervention would, in all likelihood, be accessible to a wide majority of pregnant women as outpatient procedures and from an early point in gestation, thus potentially maximizing impact. It would also constitute an original provider-based model of personalized perinatal stem cell processing on demand, while further qualifying amniotic cell banking as clinically meaningful. Although a variety of applications of this emerging therapeutic paradigm are conceivable and, in fact, are currently under investigation, at this time tangible experimental reports have involved the management of neural tube and abdominal wall defects.

Notwithstanding multiple experimental advances, plenty promise, and perhaps undue publicity, the fact remains that almost all new cell-based therapies suggested over the last few decades are yet to lead to significant, widespread consequence to patient care. Sole exceptions are the therapies based on harnessing and/or augmenting the biological activity that certain cells already exert in nature. Blood transfusions in their different variations and bone marrow transplantation are the most conspicuous examples of this premise. These long-proven cell-based therapies have had unmatched impact to public health, in large part owing to the fact that the cells used are to perform the very same functions that they already naturally do. An analogous correspondence also applies to TRASCET, in that it, too, is based on the therapeutic amplification of the normal biological activities of specific cells, only prenatally and in a distinct environment.

\section{BIOLOGICAL BASIS FOR TRASCET}

A biological role for any cell present in the amniotic fluid was first described only not long ago, namely an activity of amniotic fluid mesenchymal stem cells (afMSCs) in fetal wound healing (1). In sequential experiments using fetal lambs, that study showed that, although not absolutely required for the healing process, afMSCs do accelerate wound repair and enrich its extracellular matrix profile (Figure 1) (1). The mechanisms behind the fetus' long-known highly enhanced capacity to heal wounds remain to be fully understood (2). Until that study, the focus of fetal woundhealing research had solely been on the peculiarities of local molecular pathways and gene expression patterns $(3,4)$. That work shed light on a thitherto overlooked endogenous cellular constituent germane to the fetal wound-healing puzzle. Such a finding was in line with the fact that mesenchymal stem cells (MSCs) from other sources, particularly the bone 


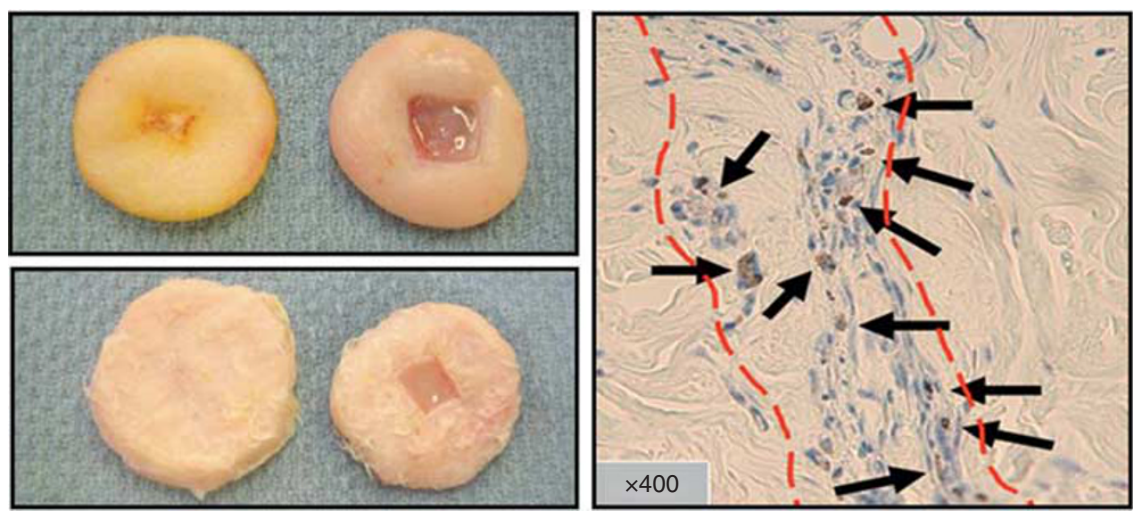

Figure 1. Representative gross views of two sets of fetal wounds, each set from the same fetal lamb, 9 (top) and 20 (bottom) days after their creation, illustrating evident differences in healing rate. The excerpted wounds on the left were exposed to amniotic fluid cells, whereas those on the right were not. The micrograph shows a fetal wound (within the dotted lines) populated by labeled autologous amniotic mesenchymal stem cells identified by monoclonal anti-GFP immunohistochemistry (arrows; original magnification $\times 400$ ). GFP, green fluorescent protein.

marrow, are known to home in to injured sites and contribute to tissue repair in postnatal life, as discussed elsewhere in this volume (5-7).

The discovery that afMSCs have a role in fetal wound healing has added a new layer to the understanding of both fetal and postnatal tissue repair. It has also lent a biological basis to the use of afMSCs in regenerative strategies, be it perinatally or later in life. Indeed, ever since the first experimental descriptions of therapeutic roles for afMSCs in the early 2000s, there has been a plethora of reports on a variety of potential applications for these cells, by countless groups (8-10). Interestingly, although TRASCET is the only one of such applications to be based on the actual biological role of these cells, it was first proposed more than a decade later. From a translational standpoint, afMSCs are plausibly more relevant to the TRASCET approach than any other stem cells, given that they are to be used in their native environment, usually in an autologous manner, and can be procured from minute samples obtained by one of the least invasive of all fetal cell procurement methods-a plain amniocentesis-which can even be already indicated for select diagnostic purposes in mothers carrying a fetus with a congenital anomaly. Nonetheless, fetal MSCs from other sources, such as the placenta, can also be viable clinically and, in fact, have already been used for TRASCET experimentally (details below).

\section{Disease-Associated Amniotic Stem Cells}

In addition to its regular population, the amniotic fluid can also harbor unique stem cells present only in the setting of certain fetal diseases (11). For example, neural stem cells (NSCs) can be isolated from the amniotic fluid in experimental models of neural tube defects (NTDs)-so-called amniotic fluid neural stem cells (afNSCs) (11). Although cells of a neural phenotype have long been known to occur in the amniotic fluid when a NTD is present, and in fact often aid in the diagnosis of these anomalies, the existence of an undifferentiated, more primitive population of neural progenitor cells within the amniotic cavity was yet to be demonstrated until that report (12-15). The presence of afNSCs in human amniotic fluid from fetuses with NTDs followed shortly thereafter, albeit so far only in the presence of anencephaly (16). The fact that the amniotic fluid may be an accessible source of (autologous) NSCs relevant to the development of new therapies for spina bifida adds another facet to the TRASCET concept. In addition, recent studies suggest that this unique population of stem cells may also have diagnostic value in the setting of congenital NTDs, besides a potential therapeutic one $(17,18)$. Certainly, the perspective of other disease-associated amniotic stem cells being eventually described, along with roles for such cells in select clinical scenarios, is now to be expected. Still, given the current relative paucity of data on disease-specific amniotic fluid stem cells, this review will focus on MSC-based TRASCET.

\section{DONOR MSC FATE AFTER TRASCET}

As discussed in other chapters, still a lot remains to be understood about the mechanisms governing MSC trafficking and its respective contributions to tissue reparation, restoration, and inflammation (19). Expectedly, the same applies to TRASCET. Although it is tempting to assume that donor cellhoming simply involves direct seeding via the amniotic fluid/ cavity, engraftment patterns observed to date have been incompatible with merely this form of cell kinetics. Indeed, it has been recently shown that, after concentrated intraamniotic injection, donor afMSCs actually home robustly to the placenta, the fetal bone marrow, and even to select sites of maternal injury, pointing to the presence of hematogenous donor cell routing $(20,21)$.

The homing of donor afMSCs to the fetal bone marrow is of particular significance, in that, from there, donor MSCs can reach virtually any area of the body/fetus, much like bone marrow MSCs in postnatal life, thus significantly expanding 
potential therapeutic applications of TRASCET well beyond only exposed structural congenital anomalies, as initially studied. The fetal bone marrow is a shifting microenvironment containing two major distinct multipotent cell populations, hematopoietic stem cells (HSCs), and MSCs. Both these cell types develop within different hematopoietic sites throughout ontogeny, suggesting a close interplay between the two systems (22). Exogenous HSC and MSC engraftment to the fetal bone marrow has long been reported after administration of these cells through the placenta, intravenously in the developing embryo or fetus, or intraperitoneally in the fetus (23). To my knowledge, fetal bone marrow engraftment of donor MSCs after plain delivery into the amniotic cavity was yet to be described until these recent studies. The chronology of placental cell trafficking noticed in the rodent model, with bimodal peaks soon after injection and at term, is suggestive of controlled cell routing, rather than passive cell clearance $(21,24)$. Besides the point of exogenous administration, the homing of HSC and MSC donor cells to the fetal bone marrow is thought to be affected by the predictable spatiotemporal and quantitative development of prenatal hematopoiesis, with sequential overlaps at different anatomical sites. In murine models, these sites include the yolk sac, aorta-gonad mesonephros region, placenta, fetal liver, fetal spleen, and ultimately the fetal bone marrow (2527). Donor HSCs are known to join host HSCs in their normal migratory pattern in the fetus (28). This phenomenon could, perhaps, also apply to MSCs, which, in turn, would suggest the intriguing possibility that amniotic fluid, placental, umbilical, and fetal bone marrow MSCs are all actually compartments of the same overarching cell pool. Of course, that remains to be definitively determined. Moreover, in light of the close relationship between HSCs and MSCs, the presence of donor MSCs in the fetal bone marrow after TRASCET submits the possibility that the amniotic cavity could also be a practical route of administration of HSCs and possibly even other donor cells for therapeutic purposes, although of course this is purely speculative at this time. Further scrutiny on these perspectives is ongoing.

It remains to be determined how long donor afMSCs that home to the mother remain viable. Yet, given the potential for both beneficial and harmful effects from fetal microchimerism in the maternal circulation, such an aspect of donor cell homing must be included in TRASCET counseling, should it become clinical reality.

\section{TRASCET APPLICATIONS}

Currently, the United States has $\sim 4$ million live births per year. Congenital anomalies are stably present in $3-4 \%$ of all newborns (29-31). Those diseases are responsible for $\sim 20 \%$ of deaths occurring in the neonatal period and even higher morbidity rates during childhood $(31,32)$. The biological basis, timing, practicality, accessibility and ethically unobjectionable nature of TRASCET all support the perspective that it could have a significant impact in the perinatal management of a variety of diseases. Yet, having been described exceedingly recently, plausibly to date only a few applications of this original paradigm have been examined in enough detail to justify a more elaborate review here, which will follow.

\section{TRASCET FOR NTDS}

NTDs derive from the failure of the neural tube to close by the fourth week of embryonic development. They are generally classified as open or closed, depending on the presence or absence of exposed neural tissue, respectively. They may affect any portion of the brain and/or spinal cord. In the vast majority of cases, isolated NTDs are multifactorial in inheritance (33). At the same time, folic acid deficiency is known to be at least a contributory factor (34). The risk of NTDs can be reduced by as much as $50-70 \%$ by folic acid supplementation during the first trimester of gestation $(35,36)$. Yet, despite mandatory folate supplementation in all cereal grain products, the overall incidence of spina bifida in the United States has remained fairly stable in the last several censuses, at 3-4:10,000 live births $(30,37)$.

Spina bifida is the most common survivable NTD. It results in both primary and secondary spinal cord damage. The former involves abnormal spinal cord development accompanying incomplete closure of the neural tube, whereas the latter stems from chemical and mechanical insults to the spinal cord openly exposed to the amniotic fluid and trauma. Several studies indicate that the secondary mechanisms are the most relevant clinically (38-48). In fact, the major morbidity associated with spina bifida has prompted the first ever prospective randomized control trial of fetal surgical treatment for a non-life-threatening congenital anomaly-the Management of Myelomeningocele Study- a multicentric trial funded by the National Institutes of Health (49). This landmark endeavor further validated years of research pointing to the major clinical impact of secondary mechanisms of spinal cord damage in this disease and showed that prenatal coverage of the lesion, although not curative, can improve outcome when compared with conventional postnatal repair, albeit only in a limited subset of maternal-fetal units (49). Another shortcoming of surgical repair is the fact that it can only be safely performed no earlier than the second half of the pregnancy and in a relatively short time window. This is already rather late into the pathophysiological process in NTDs, which, as mentioned above, starts by the fourth week of gestation. Further, fetal surgery is not without significant maternal and fetal risks, most notably prematurity from preterm labor. To this day, it is fair to say that, overall, the benefits of both pre- and postnatal interventions for spina bifida remain relatively modest. Current treatment protocols are basically supportive and target no more than minimizing additional central nervous system damage. Lifelong assistance, rehabilitation, and variable degrees of institutionalization remain the norm. In order to be more effective, new therapeutic strategies should entail accessibility to a much larger proportion of patients, feasibility early in gestation, and 


\section{Review | Fauza}

be minimally invasive, ideally promoting local regeneration. The TRASCET approach meets such requirements.

\section{Amniotic MSCs}

In three consecutive studies published as of this writing, TRASCET had some beneficial impact in a rodent model of spina bifida (50-52). All these experiments utilized timedated pregnant rat dams exposed to retinoic acid at a specific time of gestation for the induction of fetal NTD, an elegant model widely used by many groups (53). Although there were no significant differences in the overall dimensions of the spina bifida defect across controls, sham-treated animals and animals treated with TRASCET, fetuses in the latter group were significantly more likely to develop variable degrees of coverage of the defect, some complete, by a primitive form of skin lacking adnexa, documented histologically (Figure 2) (50). Labeled donor cells were identified in that group, interestingly not populating that neoskin, but rather preferably engrafting to the bone in the vicinity of the defect. Such an engraftment pattern is suggestive of two possibly complementary scenarios. One is that, also in the setting of spina bifida, donor cells may home to the fetal bone marrow-this is currently under focused investigation in this model. Another is that a paracrine effect may be at play.

The impact of TRASCET on the Chiari-II malformation associated with spina bifida was also studied in this model (51). Analyses included magnetic resonance imaging with a high resolution (submillimeter) scanner and histology. The Chiari-II malformation was assessed on magnetic resonance imaging using computer-generated specific angular and linear measurements of brainstem and cerebellar placement in relation to the baso-occipital bone and the base of the skull, respectively. Overall, there were statistically significant differences across the groups in linear and angular measurements of brainstem placement, with the untreated group displaying the highest degree of caudal displacement.
Essentially, it was shown that induced coverage of spina bifida defect by concentrated intra-amniotic delivery of afMSCs also minimizes the Chiari-II malformation in the rodent model. Although the Chiari-II was not completely reversed, these results suggested that, much like surgical/ mechanical repair, TRASCET can lessen this complication by decreasing the leakage of cerebrospinal fluid through the defect, as it became partly or totally covered, only nonsurgically.

In another study using the same model, the rates of either partial or complete coverage of the spina bifida defect were similar between groups treated with either afMSCs or placental MSCs for TRASCET (52). Notably, in that study, some percentage of coverage was also noticed in the untreated group, although quite limited and none complete. This finding supports the notion that the inherent biological activity of afMSCs constitutes a central underlying mechanism of defect coverage triggered by TRASCET, which may simply represent an augmentation of such activity via the large number of cells delivered. In fact, recent studies suggest that afMSCs may actually be consumed in the presence of NTDs $(17,18)$. Although the ontogeny of afMSCs and placental MSCs remain to be fully elucidated, there is evidence that they actually could be the same cell, possibly with normal traffic between the amniotic and placental compartments (54-56). Should this ever be definitively confirmed, it could explain the lack of difference in their effects as agents of TRASCET in that model, as well as the robust homing of donor afMSCs to the placenta during TRASCET, as previously discussed. At the same time, chorionic villus sampling is viable earlier in gestation than amniocentesis is, and, thus, in principle, could allow for the initiation of TRASCET correspondingly earlier than an afMSC-based treatment. Nevertheless, almost always the diagnosis of spina bifida is confirmed only at a time when

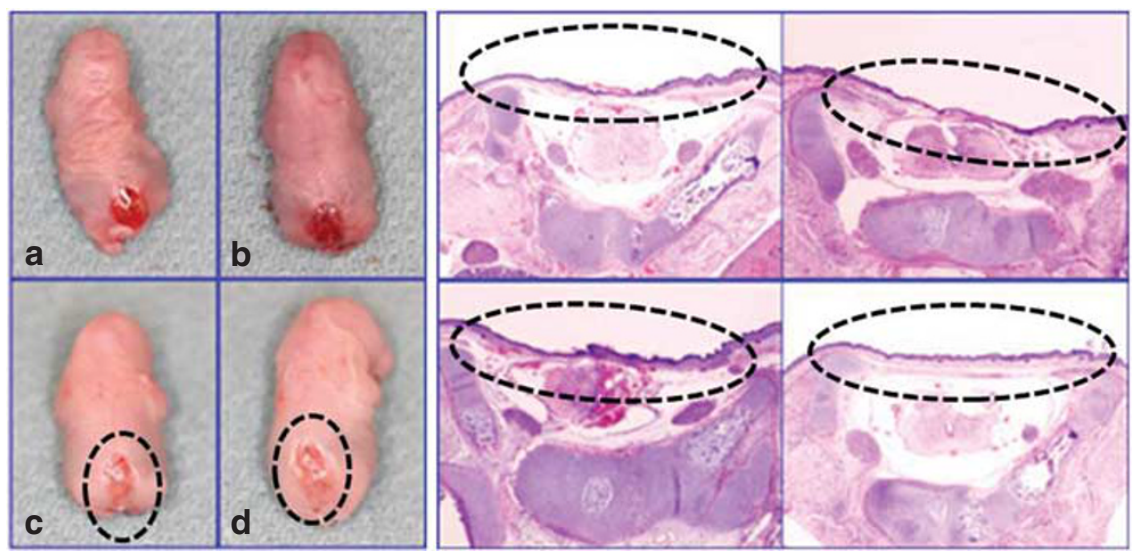

Figure 2. Gross views of spina bifida defects in term fetal rats at the time of killing. (a,b) Typical appearance from untreated and sham animals; (c,d) appearance found in some animals that received TRASCET, in which the defect appeared covered (dotted perimeters). The micrographs are from some of the TRASCET animals, showing the typical widely open vertebral arches, the spinal cord variably deformed, and coverage of the defect by a rudimentary skin with a paucity of adnexa (dotted perimeters; H\&E, original magnification $\times 200$ ). H\&E, hemotoxylin and eosin; TRASCET, Transamniotic stem cell therapy. 
amniocentesis is already feasible and safer than chorionic villus sampling.

Although the mechanisms behind these findings remain to be determined, together all these data lend support to TRASCET as a potential alternative or at least adjuvant in the prenatal management of spina bifida. An arguably comparable closure of experimental spina bifida via intraamniotic cell injections had been previously described, although only in avian eggs ex vivo and using either embryonic stem cells, or purportedly "bone marrow stem cells" (57-59). The rodent studies previously discussed constituted the first reports in vivo, in a mammal and using fetal cells, with a translational perspective. From a clinical standpoint, afMSCs seem considerably more suitable than bone marrow or embryonic stem cells. For one, bone marrow cells, particularly autologous, would only be obtainable by much more invasive methods than a simple amniocentesis. In addition, they are yet to be shown to contribute to the biological phenomena involved. As to embryonic stem cells, should they be at all effective in this setting in vivo, there are still too many biological, logistical, and ethical limitations to their use. Of note, time is a core limiting factor in the rodent model. Rat pregnancy is quite short (term $=22$ days) and intra-amniotic injections followed by high survival rates have been feasible only on gestational day 17 , which means less than a week between treatment and killing. One could reasonably speculate that the effects of the cell administrations could have been more pronounced, should it be possible to inject them earlier and/or repeatedly. Studies on larger animal models, currently ongoing, should help clarify this.

\section{Amniotic Neural Stem Cells}

Given the previously mentioned occurrence of afNSCs within the amniotic fluid in the presence of NTDs, these stem cells are also natural candidates for the TRASCET approach. Indeed, it has been shown that simple intra-amniotic injection of expanded afNSCs in rodent fetuses with spina bifida results in both the surface and deeper portions of the exposed spinal cord becoming selectively populated by these cells (60). However, it remains to be determined whether donor afNSCs delivered in this manner can promote any degree of meaningful neural tissue repair. Plausibly, autologous afNSCs could be procured by amniocenteses from fetuses with spina bifida, expanded ex vivo, and injected back into the amniotic fluid one or more times as a component of a broader TRASCET strategy to be combined with induced coverage of the defect with afMSCs or placental MSCs.

\section{TRASCET FOR ABDOMINAL WALL DEFECTS}

The combined incidence of congenital abdominal wall defects is $\sim 1$ in 2,100 live births, placing them among the most prevalent major congenital anomalies $(29,30)$. By far, the two most common forms of these diseases are omphalocele and gastroschisis, whose etiologies remain unknown. Although omphalocele is still the most common condition, the incidence of gastroschisis seems to be rising, whereas that of omphalocele has remained stable. Both defects consist of an abnormal opening of the abdominal wall at its anterior aspect. In gastroschisis, such an opening is characteristically to the right of the umbilicus and quite small, although enough to allow for typically a large volume of eviscerated structures. In omphalocele, the opening is at the very site of the umbilical ring, therefore always central, and can vary broadly in size. Although in omphalocele the eviscerated contents are covered by a sac composed of peritoneum, Wharton's jelly, and amnion, in gastroschisis that content is entirely exposed to the amniotic fluid/cavity, which ordinarily leads to extensive local chemical insult and more vulnerability to trauma. Hence, gastroschisis is associated with considerably more damage of the herniated structures when compared with omphalocele. This is particularly more pronounced in the small and large intestines, which are almost invariably herniated. The exposed bowel is grossly abnormal, edematous, inflamed, leathery, and foreshortened. On histology, all of its layers are noticeably thickened, with variable degrees of amniotic peritonitis present. This can be further compounded by constriction of the anomalous abdominal opening, leading to bowel ischemia and/or congestion and, in more severe cases, strangulation and/or atresia. Surely, clinically relevant functional consequences of such significant structural changes are to be expected. Indeed, impaired peristalsis and a very slow recovery of proper gastrointestinal function are virtually always present. The undue exposure of the bowel to the amniotic fluid, combined with local circulatory changes, have long been established as the foremost mechanisms behind the significant intestinal damage observed in gastroschisis (and in ruptured omphaloceles) $(61,62)$. A direct correlation between the intensities of the structural damage and of the functional and clinical manifestations has also been well documented (63).

Congenital abdominal wall defects are routinely diagnosed before birth with fetal ultrasound, not infrequently already in the first trimester. The distinction between omphalocele and gastroschisis is usually straightforward. Despite the relative ease in an early diagnosis, the prenatal management of these anomalies remains restricted to counseling as to the timing and type of delivery to be performed. An actual therapeutic intervention directly aimed at improving the intestinal damage and function is yet to be widely adopted. To date, either clinically or mostly only experimentally, a number of prenatal strategies have been proposed, such as amnioexchange, amniotic fluid dilution, prenatal steroid administration, induced fetal diuresis, nitric oxide donors, and even intra-uterine repair of the defect, all with quite modest results and some risks (64-68).

Two recent experimental reports on afMSC-based TRASCET for gastroschisis in rodent and leporine models were the first to propose a cell-based approach to the prenatal management of abdominal wall defects $(69,70)$. In both those studies, a gastroschisis was surgically created in either rat or rabbit fetuses. Animals were then divided into the following three groups: one with no further manipulations and two 

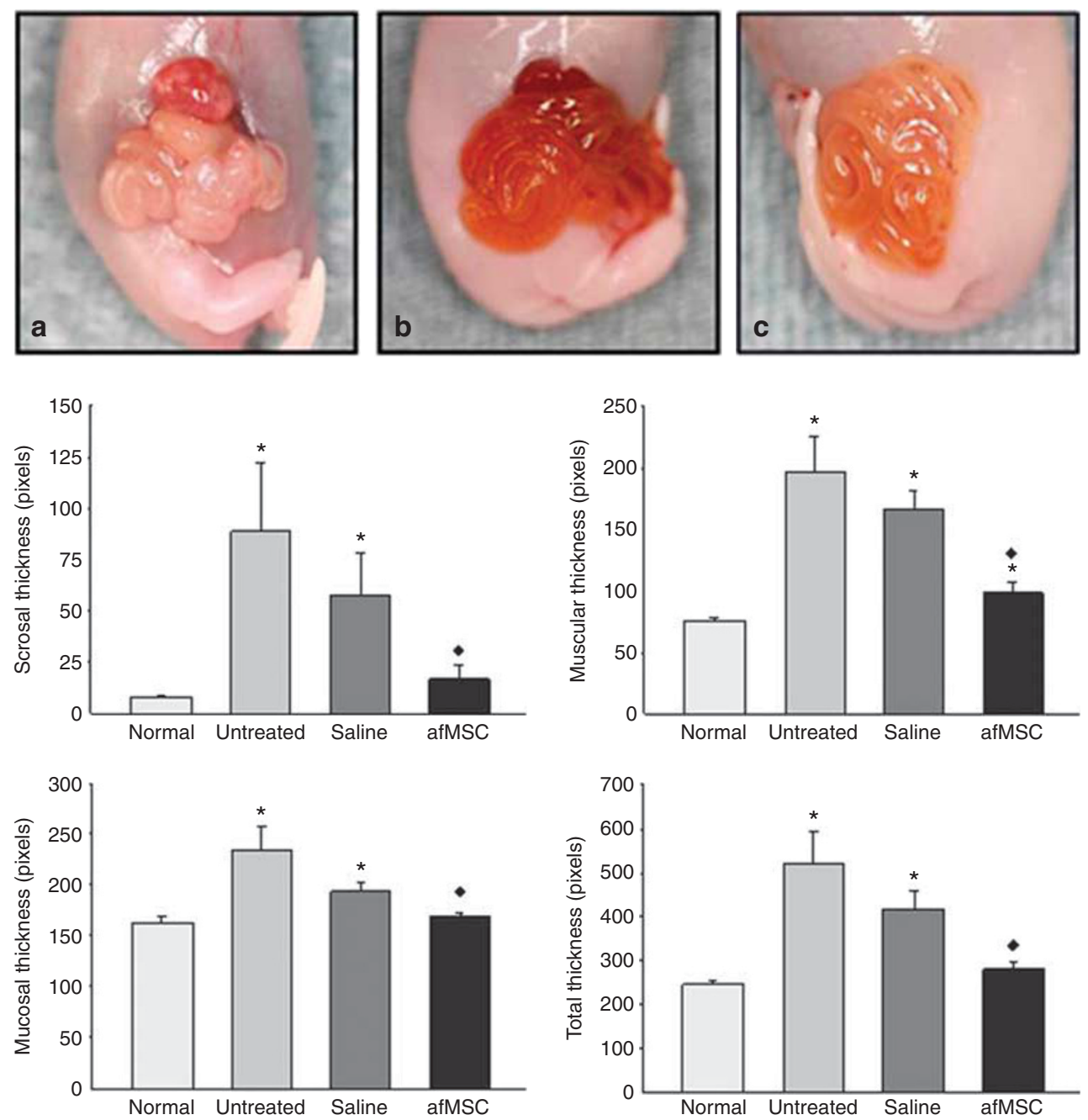

* $P<0.05$ vs.normal $\bullet P<0.05$ vs. untreated and saline groups

Figure 3. Representative gross views of term rat fetuses with gastroschisis. The exposed intestine in the (a) untreated and (b) saline groups appeared heterogeneous, edematous, and thickened. The intestine in the (c) TRASCET group seemed less affected. This was confirmed by multiple histological measurements of bowel wall thickness (graph), showing the mean total and segmental thicknesses of the intestinal wall compared across the groups. There were significant decreases in serosal, muscular, and mucosal layer thicknesses and in total bowel wall thickness in the TRASCET group vs. the untreated and saline groups. There were no such differences between the untreated and saline groups. There were no differences between the TRASCET group and normal controls, except for a significantly thicker muscular layer in the former. TRASCET, Transamniotic stem cell therapy.

receiving volume-matched intra-amniotic injections of either saline or a concentrated suspension of afMSCs at the time of operation. Non-manipulated fetuses served as normal controls. In both models, among survivors with gastroschisis there were statistically significant decreases in total bowel wall, serosal, muscular, and mucosal thicknesses-long established surrogates for bowel damage in this disease-in the afMSC group vs. the untreated and saline groups, although the bowel was not entirely normal in the TRASCET groups (Figure 3). Donor cell engraftment seemed somewhat sparse, suggesting a paracrine effect also here, although the fact that the donor cells had to be delivered concomitantly with the creation of the defect in these models, and therefore, before any actual bowel damage had ensued, could have contributed to this observation as well. Uncovering the mechanisms behind the mitigation of intestinal damage promoted by the afMSCs in that setting was beyond the scope of introductory studies such as these, yet surely this pursuit is now warranted. An eventual understanding of such mechanisms should not only enhance the translational prospects for this particular application of TRASCET, but also have an impact on other forms of cell-mediated intestinal repair.

\section{REGULATORY DEMANDS AND FUTURE DEVELOPMENT}

Although the TRASCET approach as a treatment strategy is novel, native afMSCs have been utilized therapeutically in a multitude of animal models for almost two decades now, with 
no tumor or any other ill effects having been identified to date. Compared with embryonic stem cells, afMSCs are not nearly as primitive and have been shown to be genetically and phenotypically stable under extensive cell processing performed in compliance with clinically suitable Food and Drug Administration guidelines $(71,72)$. Further, afMSCs have been shown to be expandable in culture significantly faster than other MSCs of indistinguishable phenotype, when grown under identical conditions in vitro (56). For example, a 3-5 $\mathrm{ml}$ aliquot of amniotic fluid obtainable during amniocentesis is all that would be needed for hundreds of millions of cells to be generated in 3-4 weeks' time $(71,72)$. Such a robust and stable proliferation capacity, combined with the fact that TRASCET is based on the use of afMSCs in their native, undifferentiated state, without (the need for) any added manipulation, after administration as plain cell suspensions into the very environment from which they are derived, further underscore the operability and potential scope of the TRASCET principle.

Further work in larger animals would of course be of relevance to eventual clinical translation. The extent and pattern of therapeutic benefit in larger models (and in humans) is expected to be dependable to variables such as density and volume of the cell suspension, timing and number of doses injected, and possibly also eventual targeted enhancements of the donor cells in vitro before delivery in vivo. For example, a potential benefit to pre-selecting c-kitpositive donor cells could be uncovered, among other foreseeable strategies. Data on the long-term fate of donor cells, along with mechanistic insights are needed. Such foreseeable developments notwithstanding, the results reported to date, combined with the biological basis for TRASCET, substantiate the expectation that it may become a practical, accessible, minimally invasive constituent of original regenerative strategies for the prenatal management of different birth defects.

\section{STATEMENT OF FINANCIAL SUPPORT}

The work summarized in this review was funded by the Kevin and Kate McCarey Fund for Surgical Research at Boston Children's Hospital.

Disclosure: The author declares no conflict of interest.

\section{REFERENCES}

1. Klein JD, Turner CG, Steigman SA, et al. Amniotic mesenchymal stem cells enhance normal fetal wound healing. Stem Cells Dev 2011;20: 969-76.

2. Gurtner GC, Werner S, Barrandon Y, Longaker MT. Wound repair and regeneration. Nature 2008;453:314-21.

3. Tammi R, Pasonen-Seppanen S, Kolehmainen E, Tammi M. Hyaluronan synthase induction and hyaluronan accumulation in mouse epidermis following skin injury. J Invest Dermatol 2005;124:898-905.

4. David-Raoudi M, Tranchepain F, Deschrevel B, et al. Differential effects of hyaluronan and its fragments on fibroblasts: relation to wound healing. Wound Rep Regen 2008;16:274-87.

5. Wu Y, Wang J, Scott PG, Tredget EE. Bone marrow-derived stem cells in wound healing: a review. Wound Rep Regen 2007;15 (Suppl 1): S18-26.

6. Kwong FN, Harris MB. Recent developments in the biology of fracture repair. J Am Acad Orthop Surg 2008;16:619-25.
7. Fu X, Li H. Mesenchymal stem cells and skin wound repair and regeneration: possibilities and questions. Cell Tissue Res 2009;335: $317-21$.

8. Kaviani A, Perry TE, Dzakovic A, Jennings RW, Ziegler MM, Fauza DO. The amniotic fluid as a source of cells for fetal tissue engineering. J Pediatr Surg 2001;36:1662-5.

9. Fuchs JR, Kaviani A, Oh JT, et al. Diaphragmatic reconstruction with autologous tendon engineered from mesenchymal amniocytes. J Pediatr Surg 2004;39:834- discussion-8.

10. Fauza DO, Bani M. Fetal Stem Cells in Regenerative Medicine: Principles and Translational Strategies. New York, NY, USA: Springer Science, 2016.

11. Turner CG, Klein JD, Wang J, et al. The amniotic fluid as a source of neural stem cells in the setting of experimental neural tube defects. Stem Cells Dev 2013;22:548-3.

12. Gosden CM, Brock DJ. Morphology of rapidly adhering amniotic-fluid cells as an aid to the diagnosis of neural-tube defects. Lancet 1977;1:919-22.

13. Aula P, von Koskull H, Teramo K, et al. Glial origin of rapidly adhering amniotic fluid cells. Br Med J 1980;281:1456-7.

14. Greenebaum E, Mansukhani MM, Heller DS, Timor-Tristsch I. Open neural tube defects: immunocytochemical demonstration of neuroepithelial cells in amniotic fluid. Diagn Cytopathol 1997;16:143-4.

15. Mendonca ED, Gutierrez CM, Peres LC. Brain tissue fragments in the amniotic fluid of rats with neural tube defect. Pathology 2005;37:152-6.

16. Chang YJ, Su HL, Hsu LF, et al. Isolation of human neural stem cells from the amniotic fluid with diagnosed neural tube defects. Stem Cells Dev 2015;24:1740-50.

17. Pennington EC, Gray FL, Ahmed A, Zurakowski D, Fauza DO. Targeted quantitative amniotic cell profiling: a potential diagnostic tool in the prenatal management of neural tube defects. J Pediatr Surg 2013;48: 1205-0.

18. Pennington EC, Rialon KL, Dionigi B, Ahmed A, Zurakowski D, Fauza DO. The impact of gestational age on targeted amniotic cell profiling in experimental neural tube defects. Fetal Diagn Ther 2015;37:65-9.

19. Hong HS, Lee J, Lee E, et al. A new role of substance P as an injuryinducible messenger for mobilization of $\mathrm{CD} 29(+)$ stromal-like cells. Nat Med 2009;15:425-35.

20. Graham CD, Shieh HF, Brazzo JA 3rd, Zurakowski D, Fauza DO. Donor mesenchymal stem cells home to maternal wounds after transamniotic stem cell therapy (TRASCET) in a rodent model. J Pediatr Surg 2017;52: 1006-9.

21. Shieh HF, Ahmed A, Tracy SA, Zurakowski D, Fauza DO. Fetal bone marrow homing of donor mesenchymal stem cells after transamniotic stem cell therapy (TRASCET). J Pediatr Surg 2017 (in press).

22. Mendes SC, Robin C, Dzierzak E. Mesenchymal progenitor cells localize within hematopoietic sites throughout ontogeny. Development 2005;132: $1127-36$.

23. Boelig MM, Flake AW. In utero stem cell transplantation. In: Fauza DO, Bani M, eds. Fetal Stem Cells in Regenerative Medicine: Principles and Translational Strategies. New York, NY, USA: Springer/Humana Press, 2016:317-37.

24. Derderian SC, Jeanty C, MacKenzie TC Fet-maternal cell trafficking and labor. In: Fauza DO, Bani M, eds. Fetal Stem Cells in Regenerative Medicine: Principles and Translational Strategies. New York, NY, USA: Springer/Humana Press, 2016:33-45.

25. Christensen JL, Wright DE, Wagers AJ, Weissman IL. Circulation and chemotaxis of fetal hematopoietic stem cells. PLoS Biol 2004;2:E75.

26. Medvinsky A, Dzierzak E. Definitive hematopoiesis is autonomously initiated by the AGM region. Cell 1996;86:897-906.

27. Mikkola HK, Gekas C, Orkin SH, Dieterlen-Lievre F. Placenta as a site for hematopoietic stem cell development. Exp Hematol 2005;33:1048-54.

28. Vrecenak JD, Flake AW. In utero hematopoietic cell transplantationrecent progress and the potential for clinical application. Cytotherapy 2013;15:525-35.

29. Egbe A, Lee S, Ho D, Uppu S, Srivastava S. Racial/ethnic differences in the birth prevalence of congenital anomalies in the United States. J Perinat Med 2015;43:111-7. 
30. Mohamed MA, Aly H. Birth region, race and sex may affect the prevalence of congenital diaphragmatic hernia, abdominal wall and neural tube defects among US newborns. J Perinatol 2012;32:861-.

31. Parker SE, Mai CT, Canfield MA, et al. Updated national birth prevalence estimates for selected birth defects in the United States, 2004-2006. Birth Defects Res A Clin Mol Teratol 2010;88:1008-6.

32. Cragan JD, Gilboa SM. Including prenatal diagnoses in birth defects monitoring: experience of the metropolitan atlanta congenital defects program. Birth Defects Res A Clin Mol Teratol 2009;85:20-9.

33. Main DM, Mennuti MT. Neural tube defects: issues in prenatal diagnosis and counselling. Obstetr Gynecol 1986;67:1-16.

34. Botto LD, Moore CA, Khoury MJ, Erickson JD. Neural-tube defects. N Engl J Med 1999;341:1509-9.

35. MRC Vitamin Study Research Group. Prevention of neural tube defects: results of the Medical Research Council Vitamin Study. Lancet 1991;338: $131-7$.

36. Czeizel AE, Dudas I. Prevention of the first occurrence of neural-tube defects by periconceptional vitamin supplementation. N Engl J Med 1992;327:1832-5.

37. Boulet SL, Yang Q, Mai C, et al. Trends in the postfortification prevalence of spina bifida and anencephaly in the United States. Birth Defects Res A Clin Mol Teratol 2008;82:527-32.

38. Patten BM. Embryological stages in the establishing of myeloschisis with spina bifida. Am J Anat 1953;93:365-95.

39. Osaka K, Tanimura T, Hirayama A, Matsumoto S. Myelomeningocele before birth. J Neurosurg 1978;49:711-24.

40. Hutchins GM, Meuli M, Meuli-Simmen C, Jordan MA, Heffez DS, Blakemore KJ. Acquired spinal cord injury in human fetuses with myelomeningocele. Pediatr Pathol Lab Med 1996;16:701-12.

41. Meuli M, Meuli-Simmen C, Hutchins GM, Seller MJ, Harrison MR, Adzick NS. The spinal cord lesion in human fetuses with myelomeningocele: implications for fetal surgery. J Pediatr Surg 1997;32:448-52.

42. Korenromp MJ, van Gool JD, Bruinese HW, Kriek R. Early fetal leg movements in myelomeningocele. Lancet 1986;1:917-8.

43. Sival DA, Begeer JH, Staal-Schreinemachers AL, Vos-Niel JM, Beekhuis JR, Prechtl HF. Perinatal motor behaviour and neurological outcome in spina bifida aperta. Early Hum Dev 1997;50:27-37.

44. Luthy DA, Wardinsky T, Shurtleff DB, et al. Cesarean section before the onset of labor and subsequent motor function in infants with meningomyelocele diagnosed antenatally. N Engl J Med 1991;324:662-.

45. Shurtleff DB, Luthy DA, Nyberg DA, Benedetti TJ, Mack LA. Meningomyelocele: management in utero and post natum. Ciba Found Symp 1994;181:270-80.

46. Meuli M, Meuli-Simmen C, Yingling CD, et al. Creation of myelomeningocele in utero: a model of functional damage from spinal cord exposure in fetal sheep. J Pediatr Surg 1995;30:1028-32 discussion 32-3.

47. Meuli M, Meuli-Simmen C, Hutchins GM, et al. In utero surgery rescues neurological function at birth in sheep with spina bifida. Nat Med 1995;1: $342-7$.

48. Meuli M, Meuli-Simmen C, Yingling CD, et al. In utero repair of experimental myelomeningocele saves neurological function at birth. J Pediatr Surg 1996;31:397-402.

49. Adzick NS, Thom EA, Spong CY, et al. A randomized trial of prenatal versus postnatal repair of myelomeningocele. N Engl J Med 2011;364: 993-1004.

50. Dionigi B, Ahmed A, Brazzo J 3rd, Connors JP, Zurakowski D, Fauza DO. Partial or complete coverage of experimental spina bifida by simple intraamniotic injection of concentrated amniotic mesenchymal stem cells. J Pediatr Surg 2015;50:69-73.

51. Dionigi B, Brazzo JA 3rd, Ahmed A, et al. Trans-amniotic stem cell therapy (TRASCET) minimizes Chiari-II malformation in experimental spina bifida. J Pediatr Surg 2015;50:1037-41.

52. Feng C, D Graham C, Connors JP, Brazzo 3rdJ, Zurakowski D, Fauza DO. A comparison between placental and amniotic mesenchymal stem cells for transamniotic stem cell therapy (TRASCET) in experimental spina bifida. J Pediatr Surg 2016;51:1010-3.

53. Danzer E, Schwarz U, Wehrli S, Radu A, Adzick NS, Flake AW. Retinoic acid induced myelomeningocele in fetal rats: characterization by histopathological analysis and magnetic resonance imaging. Exp Neurol 2005;194:467-75.

54. Fauza DO. Amniotic fluid and placental stem cells. Best Pract Res Clin Obstet Gynaecol 2004;18:877-91.

55. Klein JD, Fauza DO. Amniotic and placental mesenchymal stem cell isolation and culture. Methods Mol Biol 2011;698:75-88.

56. Kunisaki SM, Fuchs JR, Steigman SA, Fauza DO. A comparative analysis of cartilage engineered from different perinatal mesenchymal progenitor cells. Tissue Eng 2007;13:2633-44.

57. Lee DH, Kim EY, Park S, et al. Reclosure of surgically induced spinal open neural tube defects by the intraamniotic injection of human embryonic stem cells in chick embryos 24 hours after lesion induction. J Neurosurg 2006;105:127-33.

58. Lee DH, Park S, Kim EY, et al. Enhancement of re-closure capacity by the intra-amniotic injection of human embryonic stem cells in surgically induced spinal open neural tube defects in chick embryos. Neurosci Lett 2004;364:98-100.

59. Lee DH, Phi JH, Kim SK, Cho BK, Kim SU, Wang KC. Enhanced reclosure of surgically induced spinal open neural tube defects in chick embryos by injecting human bone marrow stem cells into the amniotic cavity. Neurosurgery 2010;67:129-35.

60. Turner CG, Pennington EC, Gray FL, Ahmed A, Teng YD, Fauza DO. Intra-amniotic delivery of amniotic-derived neural stem cells in a syngeneic model of spina bifida. Fetal Diagn Ther 2013;34:38-43.

61. Langer JC, Longaker MT, Crombleholme TM, et al. Etiology of intestinal damage in gastroschisis. I: Effects of amniotic fluid exposure and bowel constriction in a fetal lamb model. J Pediatr Surg 1989;24:992-7.

62. Logghe HL, Mason GC, Thornton JG, Stringer MD. A randomized controlled trial of elective preterm delivery of fetuses with gastroschisis. J Pediatr Surg 2005;40:1726-31.

63. Luton D, de Lagausie P, Guibourdenche J, et al. Effect of amnioinfusion on the outcome of prenatally diagnosed gastroschisis. Fetal Diagn Ther 1999;14:152-5.

64. Bittencourt DG, Barreto MW, Franca WM, Goncalves A, Pereira LA, Sbragia L. Impact of corticosteroid on intestinal injury in a gastroschisis rat model: morphometric analysis. J Pediatr Surg 2006;41:547-3.

65. Goncalves FL, Bueno MP, Schmidt AF, Figueira RL, Sbragia L. Treatment of bowel in experimental gastroschisis with a nitric oxide donor. Am J Obstet Gynecol 2015;212 (383): e1-7.

66. Hakguder G, Ates O, Olguner M, et al. Induction of fetal diuresis with intraamniotic furosemide increases the clearance of intraamniotic substances: an alternative therapy aimed at reducing intraamniotic meconium concentration. J Pediatr Surg 2002;37:1337-42.

67. Till $\mathrm{H}$, Muensterer $\mathrm{O}$, Mueller $\mathrm{M}$, et al. Intrauterine repair of gastroschisis in fetal rabbits. Fetal Diagn Ther 2003;18:297-300.

68. Yu J, Gonzalez-Reyes S, Diez-Pardo JA, Tovar JA. Effects of prenatal dexamethasone on the intestine of rats with gastroschisis. J Pediatr Surg 2003;38:1032-5.

69. Feng C, Graham CD, Connors JP, et al. Transamniotic stem cell therapy (TRASCET) mitigates bowel damage in a model of gastroschisis. J Pediatr Surg 2016;51:56-61.

70. Feng C, Graham CD, Shieh HF, et al. Transamniotic stem cell therapy (TRASCET) in a leporine model of gastroschisis. J Pediatr Surg 2017;52: 30-4.

71. Kunisaki SM, Armant M, Kao GS, Stevenson K, Kim H, Fauza DO. Tissue engineering from human mesenchymal amniocytes: a prelude to clinical trials. J Pediatr Surg 2007;42:974-9.

72. Steigman SA, Armant M, Bayer-Zwirello L, et al. Preclinical regulatory validation of a 3-stage amniotic mesenchymal stem cell manufacturing protocol. J Pediatr Surg 2008;43:1164-9. 